\title{
Adhesion of veneering resins to polymethylmethacrylate-based CAD/CAM polymers after various surface conditioning methods
}

\author{
Stawarczyk, B ; Trottmann, A ; Hämmerle, C H F ; Özcan, Mutlu
}

\begin{abstract}
Objectives. The aims of this study were to test whether the bond strength of a hybrid composite and a PMMA-based veneer to CAD/CAM polymers would improve after pre-treatment and to evaluate the failure types after debonding. Materials and methods. Three types of PMMA-based (CAD-Temp, artBloc Temp and TelioCAD) $\mathrm{CAD} / \mathrm{CAM}$ blocks were obtained $(\mathrm{N}=360, \mathrm{n}=15$ per test group). They were divided into four groups to be conditioned with the following methods: (a) no-treatment, (b) air-abrasion $(50 \mu \mathrm{m} \mathrm{Al}(2) \mathrm{O}(3))$, (c) air-abrasion (50 $\mu \mathrm{m} \mathrm{Al}(2) \mathrm{O}(3))+$ MPS-Silane (Monobond S) + Adhesive resin (StickResin) (for Gradia)/MMA (for Integral Esthetic Press) application, (d) Silica coating and silanization (CoJet-System). The conditioned surfaces were veneered with a hybrid composite (Gradia) or a PMMA-based resin (Integral esthetic press). After water storage (1 week, $37^{\circ} \mathrm{C}$ ), the bond strength was measured. Data were analyzed using 3-way ANOVA and post-hoc Scheffé test ( $\alpha$ $=0.05$ ). Results. Surface-conditioning method, veneer type and CAD/CAM polymers significantly affected the results. Hybrid composite did not bond to non-conditioned CAD/CAM polymers. Regardless of the conditioning method, PMMA-based resin showed significantly higher bond strength to all CAD/CAM polymers compared to hybrid composite. Air-abrasion increased the bond strength in all tested groups. Additional silane application after air-abrasion did not significantly increase the bond strength of hybrid composite. While exclusively adhesive failures were observed between the hybrid composite and the CAD/CAM polymers, PMMA veneer demonstrated cohesive failures in the $\mathrm{CAD} / \mathrm{CAM}$ polymers. Conclusion. CAD/CAM polymers could be veneered with only a PMMA-based veneer with and without air-abrasion.
\end{abstract}

DOI: https://doi.org/10.3109/00016357.2012.757354

Posted at the Zurich Open Repository and Archive, University of Zurich

ZORA URL: https://doi.org/10.5167/uzh-79688

Journal Article

Accepted Version

Originally published at:

Stawarczyk, B; Trottmann, A; Hämmerle, C H F; Özcan, Mutlu (2013). Adhesion of veneering resins to polymethylmethacrylatebased CAD/CAM polymers after various surface conditioning methods. Acta Odontologica Scandinavica, 71(5):11421148.

DOI: https://doi.org/10.3109/00016357.2012.757354 


\section{Adhesion of Veneering Resins to Polymethylmethacrylate-Based CAD/CAM}

Polymers after Various Surface Conditioning Methods

Short title: Bond strength of veneering resins to CAD/CAM polymers

Stawarczyk B, Trottmann A, Hämmerle CHF, Özcan M

Key words: polymeric block, CAD/CAM polymers, bond strength, veneering resin, hybrid composite

\section{Abstract}

Objectives. The aims of this study were to test whether the bond strength of a hybrid composite and a PMMA-based veneer to CAD/CAM polymers would improve after pretreatment, and to evaluate the failure types after debonding. Material and methods. Three types of PMMA-based (CAD-Temp, artBlock Temp and TelioCAD) CAD/CAM blocks were obtained ( $N=360, n=15$ per test group). They were divided into four groups to be conditioned with following methods: a) no-treatment, b) airabrasion $\left(50 \mu \mathrm{m} \mathrm{Al}_{2} \mathrm{O}_{3}\right)$, c) air-abrasion $\left(50 \mu \mathrm{m} \mathrm{Al} \mathrm{O}_{3}\right)+\mathrm{MPS}$-Silane (Monobond $\left.\mathrm{S}\right)+$ Adhesive resin (StickResin) (for Gradia) / MMA (for Integral Esthetic Press) application, d) Silica coating and silanization (CoJet-System). The conditioned surfaces were veneered with a hybrid composite (Gradia) or a PMMA-based resin (Integral esthetic press). After water storage ( 1 week, $\left.37^{\circ} \mathrm{C}\right)$, the bond strength was measured. Data were analysed using 3-way ANOVA and post-hoc Scheffé test (alpha=0.05). Results. Surface-conditioning method, veneer type and CAD/CAM polymers significantly affected the results. Hybrid composite did not bond to nonconditioned CAD/CAM polymers. Regardless of the conditioning method, PMMA- 
based resin showed significantly higher bond strength to all CAD/CAM polymers compared to hybrid composite. Air-abrasion increased the bond strength in all tested groups. Additional silane application after air-abrasion did not significantly increased the bond strength of hybrid composite. While exclusively adhesive failures were observed between the hybrid composite and the CAD/CAM polymers, PMMA veneer demonstrated cohesive failures in the CAD/CAM polymers. Conclusion. CAD/CAM polymers could be veneered with only a PMMA-based veneer with and without airabrasion.

\section{Introduction}

The CAD/CAM technology offers the possibility to produce dental restorations by means of numeric controlled machining. Today, as an alternative to ceramics industrially polymerized resins are introduced for dental reconstructions that can be processed with lower expenditure of time and costs [1]. Depending on the manufacturer, such materials are usually microfiller reinforced polyacrylate, polymethylmethacrylate (PMMA) with an organic modified polymer network, filled or unfilled PMMA polymers. The polymerization type has a high impact on mechanical properties of resin materials [2]. Since these CAD/CAM blocks are industrially polymerized under high pressure and temperature, they present higher mechanical properties compared to the conventional polymerized resins [1,3-5]. Nevertheless, limited information is available on their mechanical durability with and without aging regimens $[1,3,4]$. Basaran at al. [4] compared the initial fracture load of manually fabricated and CAD/CAM milled 3-unit FDPs where CAD/CAM milled fixed dental prostheses (FDPs) revealed a higher fracture load than manually polymerized ones. Alt et al. [1] reported that after 3 months' of water storage at $37^{\circ} \mathrm{C}$ and 5000 cycles thermocycling, polymeric CAD/CAM FDPs showed significantly higher fracture load 
compared to manually fabricated ones. Stawarczyk et al. [5] tested the fracture load of milled and conventionally fabricated polymeric and glass-ceramic FDPs after saliva storage up to 180 days and after chewing simulation up to 1.2 Mio cycling. The authors observed that aging did not influence the fracture load of FDPs made of CAD/CAM polymers. FDPs made of glass-ceramic showed significantly lower fracture load than those of all resin FDPs. Therefore CAD/CAM polymers could be alternative materials to glass-ceramic for FDP constructions.

At this time, most of the polymeric CAD/CAM blocks are bulk polymeric materials in one colour. When these bulk polymeric materials are indicated for long-term use, their veneering with conventional veneering resins is of importance to improve the aesthetic outcome. Therefore, after milling polymeric CAD/CAM frameworks, they can be veneered using layering technique with PMMA or conventional dimethacrylate resin based materials. To the authors' best knowledge, at present, there is no information available on the bond stability of veneering resins to industrially polymerized CAD/CAM polymers. One of the most common methods to condition PMMA-based materials is the use of air-borne particle abrasion with alumina or alumina coated silica particles followed by silanization, which in principle cleans the substrate surface and at the same time increases the surface area $[6,7]$. One other method is the use of adhesive resin to wet the PMMA as recommended for denture tooth adhesion to PMMA [8]. When a solvent, such as MMA monomer comes in contact with a polymer, the surface of the polymer swells because of diffusion of the solvent into the polymer [9]. The diffusion is dependent on time, temperature, type of solvent, and the polymeric structure and glass transition temperature $(\mathrm{Tg})$ of the polymer. Because PMMA-based CAD/CAM blocks are composed of various phases such as polymer matrix, interpenetrating polymer network (IPN), and polymer beads, the swelling of the surface of the block is affected by several factors [9]. Higher 
diffusion rate of monomers may cause higher bond strength between the CAD/CAM block and veneering resin. In general, the bonding mechanism polymers and resin systems included mechanical and adhesive properties, dissolving bonding and secondary IPN bonding.

The objectives of this study were a) to test whether the bond strength of a hybrid composite and PMMA-based veneering to three polymeric CAD/CAM materials would improve after surface conditioning methods, and b) to evaluate the failure types after debonding. The null-hypothesis tested was that bond strength results using PMMA-based resin or hybrid composite show similar values after all pretreatment methods.

\section{Material and methods}

Three types of PMMA-based (CAD-Temp, artBlock Temp and TelioCAD) CAD/CAM polymers were obtained and veneered with either a hybrid composite (Gradia) or PMMA-based resin (Integral esthetic press) after different surface conditioning methods. The brands, batch numbers, manufacturers and the chemical compositions of the tested materials are listed in Table I.

\section{Specimen preparation}

The polymeric blocks were cut (thickness: $3 \mathrm{~mm}$ ) with a low-speed diamond saw (Well 3241, Well Diamantdrahtsägen, Mannheim, Germany) under water and subsequently embedded in acrylic resin (ScandiQuick, ScanDia, Hagen, Germany). Bonding surfaces were polished (Labo-Pol-21; Struers, Ballerup, Danemark) with a series of silicon carbide papers up to P4000 (Struers) under water. Before initiating the bonding procedures, the specimens were cleaned for 10 min in ultrasonic bath in 
distilled water (Bransonic Ultrasonic Cleaner 3510 E-DTH, Branson, Danbury, USA) and air-dried.

The specimens ( $N=360, n=120$ per polymeric block) were divided into four main groups according to the conditioning methods $(n=30)$. They were further divided into 2 groups depending on the two veneering resins ( $n=15$ per group).

The CAD/CAM polymer surfaces were then conditioned with one of the following surface-conditioning methods:

a) no treatment (control)

b) air-abrasion with alumina with mean particle size of $50 \mu \mathrm{m}$ (LEMAT NT4, Wassermann, Hamburg, Germany) for $10 \mathrm{~s}$ at a pressure of $200 \mathrm{kPa}$ from a distance of approximately $10 \mathrm{~mm}$

c) air-abrasion as described for group b, followed by the application of an MPS silane (Monobond S, Ivoclar Vivadent, Schaan, Liechtenstein) and adhesive resin (StickResin, Stick Tech, Turku, Finland) was applied for 10 s and subsequently for 20 s (Elipar S10, 3M ESPE, Seefeld, Germany) according to the manufacturers instructions before placement of the hybrid composite Gradia (GC Europe, Leuven, Belgium). For PMMA-based resin (Integral esthetic press, Merz Dental, Lütjenburg, Germany) only methylmethacrylate monomer (Integral esthetic press, Merz Dental) was applied for 5 minutes with microbrush.

d) silica coating (CoJet System, 3M ESPE) was applied with the parameters described in group b. Then an MPS silane (ESPE Sil, 3M ESPE) was applied and waited for its evaporation for 5 minutes.

An acrylic mold with an inner diameter of $2.9 \mathrm{~mm}(\mathrm{D}+\mathrm{R}$ Tec, Birmensdorf, Switzerland) was pressed onto the specimen's surface by means of a special holding device. Veneering resin was filled into the opening of the acrylic mold up to $1.5 \mathrm{~mm}$ 
and polymerized according to the manufacturers' instructions of the veneering resins. Hybrid composite (Gradia) was polymerized in a polymerization device (LABOLIGHT LV-III, GC Europe, Leuven, Belgium) for $5 \mathrm{~min}$. On the other hand, PMMA-based veneering resin (Integral esthetic press) was polymerized under pressure in water (30 $\min , 45^{\circ} \mathrm{C}, 2.5$ bar, Ivomat, Ivoclar Vivadent).

The bonded specimens were then stored in distilled water at $37^{\circ} \mathrm{C}$ for 7 days.

\section{Bond strength measurement}

For shear bond strength tests the specimens were positioned in the sample's holder with the substrate surface parallel to the loading jig (Zwick/Roell Z010, Zwick, UIm, Germany). The chisel of the loading jig was adjusted and the load was applied at a crosshead speed of $1 \mathrm{~mm} / \mathrm{min}$ to the interface close to the substrate. The load at failure was recorded and the bond strength values were calculated according to the following equation $\sigma=F / A$

$\sigma$ : shear bond strength, $\mathrm{F}$ : load at fracture $(\mathrm{N}), \mathrm{A}$ : adhesive area $\left(\mathrm{mm}^{2}\right)$

\section{Failure types}

The failure types were analyzed under a stereomicroscope (M3B, Wild, Heerbrugg, Switzerland) after debonding and classified as follows: i) adhesive - between the substrate and the veneering resin; ii) cohesive in the veneering resin; and iii) cohesive in the CAD/CAM resin. Additionally, representative specimens were then gold sputtered and the failure types were analyzed under a Scanning Electron Microscopy (SEM, Carl Zeiss Supra 50 VP FESEM, Carl Zeiss, Oberkochen, Germany). SEM was operated at $20 \mathrm{kV}$ and with a working distance of $50 \mathrm{~mm}$. 


\section{Statistical analysis}

Descriptive statistics and for the mean shear bond strength the $95 \%$ confidence intervals $(95 \% \mathrm{Cl})$ were computed. Three-way ANOVA was used for the shear bond strength values with respect to surface conditioning methods, veneering resin types and CAD/CAM resin materials. All results from the statistical analysis with $p$-values smaller than $5 \%$ were considered to be statistically significant. The Statistical Package of Social Science Version 20 (SPSS INC, Chicago, IL, USA) was used to perform statistical analysis.

\section{Results}

Mean, standard deviations and $95 \%$ confidence intervals of the shear bond strength values of all tested groups are summarized in Table II.

Surface conditioning methods $(p<0.001)$ veneering resin types $(p<0.001)$ and polymeric block $(p=0.032)$ had a significant affect on the bond strength results (Table III). Hybrid composite veneering resin did not bond to non-conditioned CAD/CAM polymers. Regardless of the conditioning method, PMMA-based veneering resin showed significantly higher bond strength for all CAD/CAM polymers (25.8 - 44.2 $\mathrm{MPa})(p<0.001)$ than the hybrid composite veneering resin $(0-8.1 \mathrm{MPa})$. Airabrasion increased the bond strength of all tested groups (4.9 - 42.9 $\mathrm{MPa})$ $(p<0.001)$. Additional silane application after air-abrasion did not significantly increased the bond strength of hybrid composite (5.0 - 7.1 MPa) $(p>0.05)$ (Fig. 1).

While exclusively adhesive failures (100\%) were observed between the hybrid veneering composite and the CAD/CAM polymers, PMMA veneer material demonstrated cohesive (100\%) failures in the CAD/CAM polymers in all groups (Fig. 2). 


\section{Discussion}

The hybrid composite veneering showed no adhesion to non-conditioned polymeric blocks. Air-abrasion of CAD/CAM polymers increased the shear bond strength for both, PMMA-based and hybrid composite veneering resins. Therefore, the hypothesis is rejected. Air-abrasion principally cleans and increases the surface area resulting in higher bond strength due the mechanical retention [6,7]. Based on the results of this study, the adhesion between the polymeric blocks and the veneering resins could be mainly attributed to mechanical retention. In the air-abraded groups additional use of adhesive promoters did not increase the bond strength compared to air-abrasion only. This indicated that micromechanical retention was sufficient to obtain adequate results.

The polymeric CAD/CAM blocks are industrially polymerized and present high degree of conversion compared to manually polymerized ones [10]. Since the nontreated polymeric blocks combined with hybrid composite showed no adhesion, it can be stated that free radicals were not sufficient to achieve adhesion between this hybrid composite and the CAD/CAM polymers materials. One study investigated the tensile strength of PMMA-based CAD/CAM crowns bonded using different resincomposite cements to dentin [11]. While air-abraded polymeric crowns bonded using resin-composites presented lower tensile strength values (1.0-2.8 MPa), non-treated polymeric crowns showed values of $0 \mathrm{MPa}$.

Prepolymerized PMMA materials are also used in removable prosthesis as denture teeth materials. In previous studies, industrially polymerized PMMA-based denture teeth bonded better to PMMA than to composite denture base materials $[8,12,13]$. On the other hand, wetting the PMMA-based denture teeth with a bonding agent increased the bond strength to photo-polymerized denture base [13-15]. In this 
study, in contrast to the hybrid composite, PMMA-based veneering resin showed higher adhesion to the CAD/CAM polymers. In fact, the PMMA material is a mixture of monomer liquid and polymer powder. Therefore, it is possible that the monomer liquid dissolved the polymeric surface and released free radicals that might have increased the adhesion of PMMA-based veneering. Similarly, previous studies reported that the pretreatment of industrially polymerized denture teeth when conditioned with methylmethacrylate monomer liquid during the processing, yielded significantly higher bond strength values to PMMA denture base than those of other surface treatment methods [16-18]. Other studies reported that the application time of the MMA liquid on the PMMA substrate surface affected the bond strength values [19-22]. The PMMA liquid application time on the substrate surface before applying the autopolymerized resin increased the bond strength [19]. In a previous study a linear regression between MMA wetting time and thickness of the swollen layer for the autopolymerized and heat-activated polymers was observed [19]. In our study, the wetting time of the polymer surface with MMA was $300 \mathrm{~s}$. The used MMA liquid of the PMMA-based veneering resin and for the conditioning liquid used for the CAD/CAM polymers was the same. Possibly due to this reason, no additional effect of methylmethacrylate monomer application was obtained. Other studies about bond between denture teeth materials and denture base polymers reported that by increasing of the polymerization temperature, the monomers of the denture base polymers diffused more effectively into acrylic resin polymer teeth and increased the bond strength $[9,23]$. Increase of the polymerization temperature of the used veneering resins may lead to the higher bond strength values to the CAD/CAM polymeric blocks.

Future studies should also assess the effect of long-term aging of the bonded CAD/CAM polymers and veneering materials. In order to achieve sufficient clinical 
long-term adhesion, the bonding of hybrid composite veneering materials must be further optimized to such CAD/CAM polymers.

\section{Conclusions}

Within the limitations of this in-vitro study, the following could be concluded:

i) When CAD/CAM polymers are not conditioned, no adhesion was obtained with the hybrid composite.

ii) PMMA-based veneering presented exclusively cohesive failures in CAD/CAM polymers with and without conditioning.

iii) Air-abrasion with both alumina and alumina coated with silica followed by silanization and adhesive resin application increased the bond strength values significantly for the hybrid composite compared to control group.

iv) Air-abrasion with alumina particles increased the bond strength of PMMAbased veneering resin to CAD/CAM polymers compared to control group and to that conditioned with silica-coating and silanization.

\section{Acknowledgements}

The authors thank Merz Dental, Vita Zahnfabrik, Ivoclar Vivadent and GC Europe for their support with study materials. The authors are grateful to Mrs Jacqueline Hofmann, Center of Dental Medicine, University of Zurich, for performing the scanning electron microscopy. 


\section{REFERENCES}

1. Alt $\mathrm{V}$, Hannig M, Wöstmann B, Balkenhol M. Fracture strength of temporary fixed partial dentures CAD/CAM versus directly fabricated restorations. Dent Mater 2011;27:339-347.

2. Nguyen JF, Mogonney V, Ruse ND, Sadoun M. Resin composite blocks via high-pressure high-temperature polymerization. Dent Mater 2012 [Epub ahead of print]

3. Balkenhol M, Mautner MC, Ferger P, Wöstmann B. Mechanical properties of provisional crown and bridge materials: chemical-curing versus dual curing systems. J Dent 2008;36:15-20.

4. Göncü Basaran E, Ayna E, Vallittu PK, Lassila LV. Load -baring of handmade and computer-aided design-computer-aided manufacturing-fabricated tree-unit fixed dental prostheses of particulate filler composite. Acta Odontol Scand 2011;69:144-150.

5. Stawarczyk B, Ender A, Trottmann A, Özcan M, Fischer J, Hämmerle CHF. Load-baring capacity of CAD/CAM milled polymeric three-unit fixed dental prostheses: Effect of aging regimens. Clin Oral Investig 2012 [Epub ahead of print]

6. Ersu B, Yuzugullu B, Ruya Yazici A, Canay S. Surface roughness and bond strengths of glass-infiltrated alumina-ceramics prepared using various surface treatments. J Dent 2009;37:848-856.

7. Marshall SJ, Bayne SC, Baier R, Tomsia AP, Marshall GW. A review of adhesion science. Dent Mater 2010;26:e11-e16.

8. Kawara M, Carter JM, Ogle RK, Johnson HH. Bonding of plastic teeth to denture base resins. J Prosthet Dent 1991;66:566-571. 
9. Vallittu PK, Ruyter IE. The swelling phenomenon of acrylic resin polymer teeth at the interface at the interface with denture base polymers. J Prosthet Dent 1997;78:194-199.

10. Pereira SG, Fulgencio R, Nunes TG, Toledano M, Osorio R, Carvalho RM. Effect of curing protocol on the polymerization of dual-cured cements. Dent Mater 2010;26:710-718.

11. Stawarczyk B, Basler T, Ender A, Roos M, Özcan M, Hämmerle CHF (2012) Effect of surface conditioning with airborne-particle abrasion on the tensile strength of polymeric CAD/CAM crowns luted with self-adhesive and conventional resin cements. J Prosthet Dent 2012;107:94-101.

12. Clancy JM, Hawkins LF, Keller JC, Boyer DB. Bond strength and failure analysis of light-cured denture resins bonded to denture teeth. J Prosthet Dent $1991 ; 65: 315-324$.

13. Cunningham JL. Shear bond strength of resin teeth to heat-cured and lightcured denture base resin. J Oral Rehabil 2000;27:312-316.

14. Hayakawa I, Hirano S, Nagao M, Matsumoto T, Masuhara E. Adhesion of a new light polymerized denture base resin to resin teeth and denture base materials. Int J Prosthodont 1991;4:561-568.

15. Yanikoglu DN, Duymus DZ, Bayindir DF. Comparative bond strength of autopolymerising denture resin and light cured composite resin to denture teeth. Int Dent J 2002;52:20-24.

16. Rached RN, Del Bel Cury AA. Heat-cured acrylic resin repaired microwarecured one: bond strength and surface texture. J Oral Rehabil 2001;28:370375.

17. Geerts GA, Jooste $\mathrm{CH}$. A comparison of the bond strength of microwave- and water bath-cured denture material. J Prosthet Dent 1993;70:406-409. 
18. Papazoglou E, Vasilas AI. Shear bond strength for composite and autopolymerized acrylic resins bonded to acrylic resin denture teeth. J Prosthet Dent 1999;82:573-578.

19. Vallittu PK, Ruyter IE. Swelling of poly(methyl methacrylate) resin at the repair joint. Int J Prosthodont 1997;10;254-258.

20. Vallittu PK, Lassila VP, Lappalainen R. Wetting the repair surface with methyl methacrylate affects the transverse strength of repaired heat-polymerized resin. J Prosthet Dent 1992;69:340-343.

21. Vallittu PK, Lassila VP, Lappalainen R. The effect of notch shape and selfcured acrylic repair on the fatigue resistance of an acrylic resin denture base. J Oral Rehabil 1996;23:108-113.

22. Vallittu PK. Some factors affected the transverse strength of repaired denture acrylic resin. Eur J Prosthodont Rest Dent 1996;4:7-9.

23. Buyukyilmaz S, Ruyter IE. Curing temperature affects acrylic denture base tooth bond. Int J Prosthodont 1997;10:49-54. 
Tables and Figure

Table I: The brands, compositions, manufacturers and batch numbers of the tested materials.

Table II: Mean (SD) and 95\% confidence intervals of shear bond strength values of all tested groups.

Table III: Three-way ANOVA results for comparison of shear bond strength relative to different surface conditioning methods, veneering resins and polymeric block types.

Figure 1. Mean shear bond strength (MPa) together with standard deviations for a.) for polymeric block CAD-Temp, b.) for polymeric block artBloc Temp, c.) for polymeric block Telio CAD.

Figure 2. SEM pictures of representative failure types. 
Table I: The brands, compositions, manufacturers and batch numbers of the tested materials.

\begin{tabular}{|c|c|c|c|}
\hline Brands & compositions & manufacturers & $\begin{array}{l}\text { Batch } \\
\text { numbers }\end{array}$ \\
\hline \multicolumn{4}{|c|}{ Polymeric CAD/CAM blocks } \\
\hline CAD-Temp & $\begin{array}{l}\text { PMMA, } 14 \% \text { micro-filled }\left(\mathrm{SiO}_{2}\right) \text {, organic } \\
\text { and anorganic pigments }\end{array}$ & $\begin{array}{l}\text { Vita Zahnfabrik, } \\
\text { Bad Säckingen, } \\
\text { Germany }\end{array}$ & 19180 \\
\hline $\begin{array}{l}\text { artBloc } \\
\text { Temp }\end{array}$ & $\begin{array}{l}\text { 99\% PMMA, unfilled, organic and } \\
\text { anorganic pigments }\end{array}$ & $\begin{array}{l}\text { Merz Dental, } \\
\text { Lütjenburg, } \\
\text { Germany }\end{array}$ & 23908 \\
\hline Telio CAD & $\begin{array}{l}\text { 99\% PMMA, unfilled, organic and } \\
\text { anorganic pigments }\end{array}$ & $\begin{array}{l}\text { Ivoclar } \\
\text { Vivadent, } \\
\text { Schaan, } \\
\text { Liechtenstein }\end{array}$ & MM1070 \\
\hline \multicolumn{4}{|c|}{ Veneering resins } \\
\hline Gradia & UDMA, EDMA, Ceramic, Prepolymer & $\begin{array}{l}\text { GC Europe, } \\
\text { Leuven, } \\
\text { Belgium }\end{array}$ & 0805122 \\
\hline $\begin{array}{l}\text { Integral } \\
\text { esthetic } \\
\text { press }\end{array}$ & $\begin{array}{l}\text { MMA, dimethacrylate, barbuturic acid } \\
\text { catalyst system, PMMA, organic and } \\
\text { inorganic pigments }\end{array}$ & $\begin{array}{l}\text { Merz Dental, } \\
\text { Lütjenburg, } \\
\text { Germany }\end{array}$ & $\begin{array}{l}1 / 44708 \\
2 / 54808\end{array}$ \\
\hline \multicolumn{4}{|c|}{ Adhesive promoters } \\
\hline $\begin{array}{l}\text { Monobond } \\
\text { S }\end{array}$ & $\begin{array}{l}\text { 3-Methyacryloxypropyl-trimethoxysilane } \\
\text { (3-MPS), ethanol / water based solvent, } \\
\text { acetic acid }\end{array}$ & $\begin{array}{l}\text { Ivoclar } \\
\text { Vivadent, } \\
\text { Schaan, } \\
\text { Liechtenstein }\end{array}$ & M51540 \\
\hline ESPE Sil & $\begin{array}{l}\text { 3-Methyacryloxypropyl-trimethoxysilane } \\
\text { (3-MPS), ethanol }\end{array}$ & $\begin{array}{l}\text { 3M ESPE, } \\
\text { Seefeld, } \\
\text { Germany }\end{array}$ & 385328 \\
\hline Stick Resin & $\begin{array}{l}\text { 2,2-bis[4-(2-hydroxy-3- } \\
\text { methacryloyloxypropoxy)] } \\
\text { phenylpropane, }\end{array}$ & $\begin{array}{l}\text { Stick Tech, } \\
\text { Turku, Finland }\end{array}$ & 5809945 \\
\hline
\end{tabular}




\begin{tabular}{|l|l|l|l|}
\hline & $\begin{array}{l}\text { Campherquinon, 2- } \\
\text { (dimethylamino)ethylmethacrylate }\end{array}$ & \\
\hline $\begin{array}{l}\text { Integral } \\
\text { esthetic } \\
\text { press liquid }\end{array}$ & $\begin{array}{l}\text { MMA, dimethacrylate, barbuturic acid } \\
\text { catalyst system }\end{array}$ & $\begin{array}{l}\text { Merz Dental, } \\
\text { Lütjenburg, } \\
\text { Germany }\end{array}$ & $2 / 54808$ \\
\hline
\end{tabular}


Table II: Mean (SD) and 95\% confidence intervals of shear bond strength values (MPa) of all tested groups.

\begin{tabular}{|l|l|l|l|l|}
\hline \multirow{5}{*}{} & Mean (SD) & $95 \%$ Cl & Mean (SD) & $95 \%$ Cl \\
\cline { 2 - 5 } & $\begin{array}{l}\text { hybrid composite } \\
\text { Gradia }\end{array}$ & $\begin{array}{l}\text { PMMA-based } \\
\text { Integral esthetic press }\end{array}$ \\
\hline \multicolumn{5}{|c|}{ CAD-Temp } \\
\hline No treatment & 0 & - & $27(3.7)$ & $(25 ; 29.1)$ \\
\hline Air-abrasion & $6(3.8)$ & $(3.9 ; 8.2)$ & $40.2(5.8)$ & $(37.2 ; 47.6)$ \\
\hline Air-abrasion with pretreatment & $7.1(3.8)$ & $(4.9 ; 9.3)$ & $35.3(4.4)$ & $(32.8 ; 37.8)$ \\
\hline Silica coating and silanization & $4.7(3.4)$ & $(2.7 ; 6.6)$ & $25.8(5.1)$ & $(22.9 ; 28.7)$ \\
\hline \multicolumn{5}{|c|}{ artBloc Temp } \\
\hline No treatment & 0 & - & $27.3(3.8)$ & $(25.1 ; 29.5)$ \\
\hline Air-abrasion & $5.3(3.4)$ & $(3.4 ; 7.3)$ & $40.3(4.4)$ & $(37.8 ; 42.8)$ \\
\hline Air-abrasion with pretreatment & $6.4(6.3)$ & $(2.8 ; 9.9)$ & $44.2(5.6)$ & $(41 ; 47.3)$ \\
\hline Silica coating and silanization & $5.5(4)$ & $(3.3 ; 7.8)$ & $28.4(2.5)$ & $(26.9 ; 29.9)$ \\
\hline \multicolumn{5}{|c}{ Telio CAD } \\
\hline No treatment & 0 & - & $33.1(5)$ & $(33.3 ; 35.9)$ \\
\hline Air-abrasion & $4.9(3.1)$ & $(3.1 ; 6.7)$ & $42.9(5.4)$ & $(39.8 ; 46)$ \\
\hline Air-abrasion with pretreatment & $5(3.7)$ & $(2.9 ; 7.1)$ & $42(5.2)$ & $(39.1 ; 44.9)$ \\
\hline Silica coating and silanization & $6.3(5.3)$ & $(3.3 ; 9.3)$ & $26.5(9)$ & $(21.5 ; 31.5)$ \\
\hline \multicolumn{5}{|l|}{}
\end{tabular}


Table III: Three-way ANOVA results for comparison of shear bond strength relative to different surface conditioning methods, veneering resins and polymeric block types.

\begin{tabular}{|l|l|l|l|}
\hline & df & Mean & S- \\
Squares & value \\
\hline Surface conditioning method & 3 & 2032 & $<0.001$ \\
\hline Veneering resin & 1 & 82971 & $<0.001$ \\
\hline Polymeric block & 2 & 70 & 0.032 \\
\hline Surface conditioning method * veneering resin & 3 & 1021 & 0.005 \\
\hline Surface conditioning method * polymeric block & 6 & 62 & 0.006 \\
\hline Veneering resin method * polymeric block & 2 & 107 & 0.005 \\
\hline Surface conditioning method * veneering resin * & 6 & 73 & 0.002 \\
polymeric block & & & \\
\hline Error & 336 & 21 & \\
\hline Total & 360 & & \\
\hline
\end{tabular}


Figure 1. Mean shear bond strength (MPa) together with standard deviations for a.) for polymeric block CAD-Temp, b.) for polymeric block artBlock Temp, c.) for polymeric block Telio CAD.

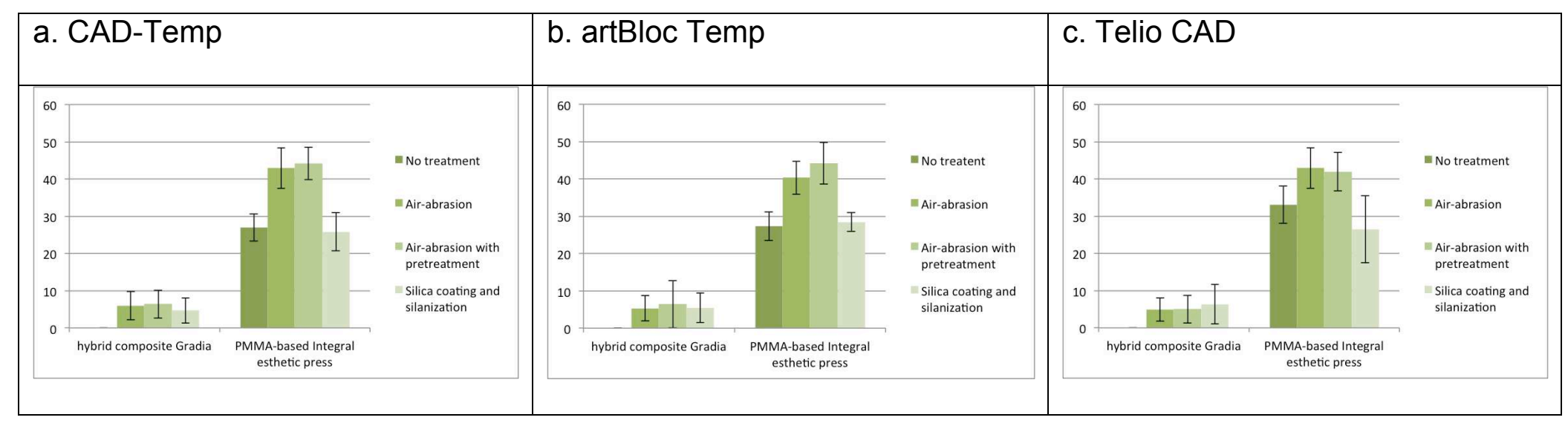


Figure 2. SEM pictures of representative failure types.

\begin{tabular}{|l|l|l|l|l|}
\hline Veneering resins & No treatment & Air-abrasion & Air-abrasion with & Silica coating and \\
\hline hybrid composite & & & & \\
Gradia & & & & \\
\hline PMMA-based Integral & & & & \\
\hline
\end{tabular}

